\section{Kidney \\ Blood Pressure Research}

Kidney Blood Press Res 2017;42:347-357

DOI: 10.1159/000477785

Published online: June 12, 2017

Accepted: March 07, 2017

This article is licensed under the Creative Commons Attribution-NonCommercial-NoDerivatives 4.0 International License (CC BY-NC-ND) (http://www.kargercom/Services/OpenAccessLicense). Usage and distribution tional License (CC BY-NC-ND) (http://www.karger.Com/Services/OpenAccessLicense). Usage and distibu
for commercial purposes as well as any distribution of modified material requires written permission.

Review

\title{
Matrix Metalloproteases in Arterial Hypertension and their Trend after Antihypertensive Treatment
}

\author{
Eugenia Hopps Rosalia Lo Presti Gregorio Caimi \\ Dipartimento Biomedico di Medicina Interna e Specialistica, Università di Palermo, Italy
}

\section{Key Words}

Matrix metalloproteases • Arterial hypertension • Vascular remodelling

\begin{abstract}
Background/Aims: Arterial hypertension is characterized by vascular remodelling, atherosclerosis and cardiovascular complications. Matrix metalloproteases (MPPs) are endopeptidases produced by all the cells present in the vascular wall and are involved in the regulation of the extracellular matrix protein turnover. MMPs contribute to blood vessel formation, remodelling, angiogenesis; whereas an altered expression or activity of MMPs or their tissue inhibitors (TIMPs) results correlated with the development and progression of cardiovascular complications. Methods: We examined the literature data regarding the role of MMPs in human hypertension, including their involvement in vascular remodelling, and the effects of some antihypertensive molecules on these MMP/TIMP profile. Results: The expression and the activity of some MMPs and TIMPs are impaired in human hypertension. An altered MMPs/TIMPs balance plays an mportant role in the vascular wall rearrangement, in response to hemodynamic changes which may induce myocardial hypertrophy and fibrosis leading to ventricular remodelling. Several studies have examined the effects of some antihypertensive molecules, such as ACE inhibitors, angiotensin receptor blockers, calcium-channel blockers, and aldosterone antagonists, on the MMPs/TIMPs profile by obtaining positive results. Conclusion: Considering the data taken into consideration, the authors believe that in clinical practice a strategic antihypertensive therapy directed to the MMPs profile, may be useful to decrease the risk of cardiovascular complications.
\end{abstract}




\section{Kidney Blood Pressure Research}

\section{Introduction}

Arterial hypertension is associated with vascular remodelling characterized by a rearrangement of vascular wall components, including extracellular matrix (ECM) protein, such as elastin and collagen fibres. Reciprocal interaction between vascular cells and their ECM is pivotal in blood vessel formation and remodelling [1]. Hypertensive vascular remodelling is an adaptive response to changes in the blood-pressure-induced circumferential wall stress and blood-flow-induced wall shear stress, which result in the degradation and reorganization of the vascular ECM protein, such as collagen, elastin, proteoglycan and fibronectin [2,3].

Matrix metalloproteinases (MMPs) are a large variety of endopeptidases involved in ECM protein degradation by cleavage of internal peptide bonds. Each MMP has a specific substrate target that defines its denomination, such as collagenase, gelatinase, stromelysin and matrilysin.

Collagenases (MMP-1, -8, -13, and -18) cleave interstitial collagen I, II, and III, and also other molecules, such as bradykinin and angiotensin I. Fragments of collagen are then degraded by gelatinases [4]: MMP-2 and -9 are secreted by several vascular cell types, including endothelial cells, pericytes and podocytes, fibroblasts and myofibroblasts, monocyte derived macrophages and local macrophages tissue [5]. They are responsible for IV type collagen degradation, vasculature remodelling, angiogenesis, inflammation and atherosclerotic plaque rupture [6, 7]. MMP-2 is constitutively expressed on cell surface, while MMP-9 is stored in secretory granules in different cell types and it is inducible by exogenous stimuli [5, 8]. Stromelysin-1 (MMP-3) and -2 (MMP-10) degrade the fibronectin, laminin, gelatins-I, III, IV and V, collagen fibers, and proteoglycans [6]. Matrilysins may hydrolize fibronectin, gelatins [6] and may cleave plasminogen producing a fragment that inhibits angiogenesis. Membrane-Type MMPs (MT-MMPs), transmembrane or GPI (glycosylphosphatidylinositol)-anchored, can degrade type-I, -II, and III collagen and other components of ECM [4]. The regulation of MMPs synthesis and activity is highly complex. Radical oxygen species (ROS), growth factors, cytokines and hormones can influence MMP transcription through the activation of the Mitogen-Activated Protein Kinase (MAPK), the inhibition of MAPK phosphatase, the inactivation of the histone deacetylase (involved in gene repression) or the recruitment of different chromatin remodelling factors [9].

Most of the MMPs are synthesized as precursors (pro-MMP) and must be activated to expose the catalytic domain with the $\mathrm{Zn}^{2+}$-binding site. This activation can be effected by proteolytic modifications from several proteases $[8,10]$ and also by S-glutathiolation, S-nitrosylation and phosphorylation reactions $[11,12]$ (Fig. 1).

In experimental models, some authors have demonstrated that angiotensin II could promote the expression of MMP-8 and MMP-13 by macrophages and their activity in atherosclerotic plaques [13], while others have highlighted that MMP-2 mediates angiotensin II-induced hypertension, being transcriptionally regulated by MMP-7 and by a disintegrin and metalloproteases (ADAM-17) [14]. On the contrary, MMPs activity can be underegulated by several

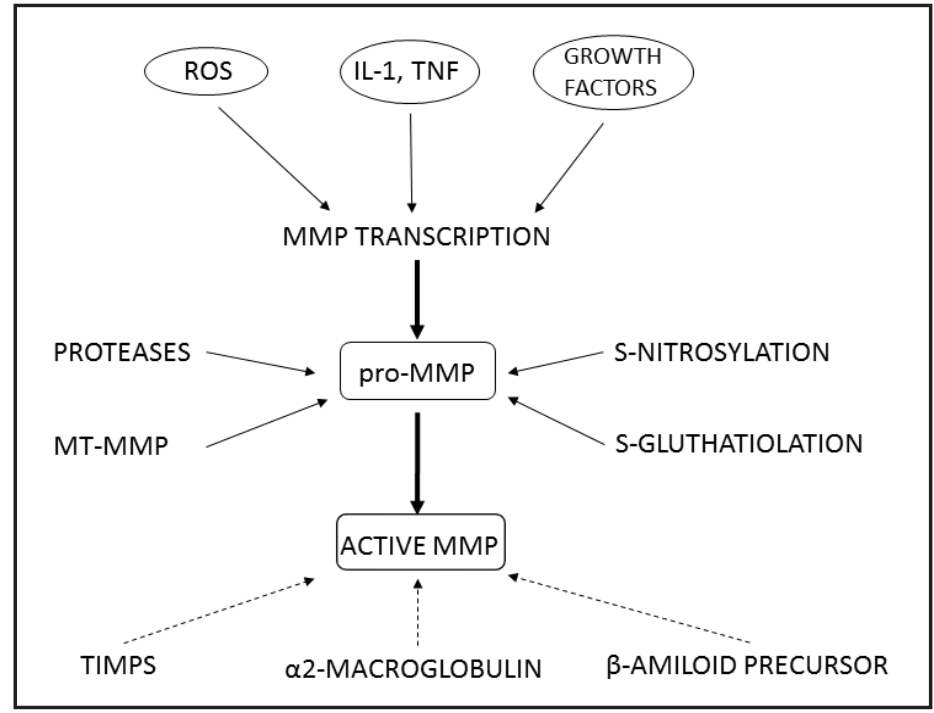

Fig. 1. Regulation of MMPs synthesis and activity. 


\section{Kidney Blood Pressure Research}

proteins, such as alpha2-macroglobulin, $\beta$-amiloid precursor protein and GPI-anchored glycoprotein, and by the four tissue inhibitors of MMP (TIMPs): TIMP-1 acts on MMP-1, MMP3, MMP-7 and MMP-9; TIMP-2 inhibits especially MMP-2; TIMP-3 can inhibit MMP-2 and MMP-9; TIMP-4 inhibits MT-1 MMP and MMP-2 activity [8, 15] (Fig. 1). TIMPs activities include regulation of cell proliferation, migration and invasion, anti-angiogenesis and apoptosis [16]. Most of these activities arise from MMP inhibition, but TIMPs are also able to interact with some specific cell receptors; for example, TIMP-3 binds vascular endothelial growth factor (VEGF) receptor on endothelial cells inhibiting angiogenesis [16].

MMPs contribute to the remodelling of basement membranes and the degradation of the components of the ECM and are involved in angiogenesis and in vascular smooth muscle cells contraction [4].

MMPs participate not only to the development of atherosclerosis, but also in its progression and in its complication: an increased MMP expression has been detected in atherosclerotic plaques and their activity may be responsible for plaque instability and rupture, and for an increased platelet aggregation [4].

Previously, we evaluated the behaviour of MMPs and TIMPs in metabolic syndrome and in obstructive sleep apnea syndrome, both conditions associated with arterial hypertension and with an elevated cardiovascular risk [17-21]. Considering that in the last decades several papers have focused on the role of MMPs and their inhibitors in arterial hypertension [22-26], our aim was to examine the literature data regarding their role in human hypertension and its complications, and the effects of some antihypertensive molecules on the MMP/ TIMP profile. Some authors have underlined that elevated levels of MMP-9 and TIMP-1 actually preceed the occurance of hypertension. By examining a population of participants to the Framingham Offspring Study, Dhingra et al have observed that subjects with higher TIMP-1 had more than double the possibility of having a hypertension occurance. In addition, there is a high risk to switch to a higher blood pressure classification, such as subjects with detectable concentration of MMP-9 [27].

\section{MMPs and hypertension-induced vascular remodelling}

Changes in blood pressure are responsible for different kinds of mechanical forces applied to the arterial wall: the thin wall hoop stress in the circumferential direction, the wall shear stress developed by blood flow and the axial stress induced by elongation in the axial direction. In response to these changes, the arterial vessels modify their thickness, composition and elastic properties [29].

Physiologically, vascular remodelling is an adaptive phenomenon of the circulatory system to changes in hemodynamic or metabolic demands, but chronically it contributes to atherosclerosis development and cardiovascular complications. The inward eutrophic remodelling is usually observed in resistance arteries in the early stages of hypertension, which is characterized by a reduction of the vessel lumen with normal media thickness and a rearrangement of vascular smooth muscle cells (VSMCs) [30, 31]. The renin-angiotensin system plays a pivotal role in vascular remodelling: angiotensin II has some effects on vascular fibroblast proliferation, ECM protein production and adhesion to matrix proteins. The hypertrophic remodelling is associated with an increase in the arterial wall thickness characterized by collagen deposition and elastin degradation, it is also common in large arteries, such as the aorta, in chronic severe hypertension [2].

MMPs play a specific role in blood vessel formation, remodelling and angiogenesis; moreover there are also some stimuli which induce MMPs expression and activation, such as oxidative stress, inflammation, angiotensin II, and hemodynamic forces [32] (Fig. 2).

In the vascular wall of hypertensive subjects, there is an accelerated turnover and deposition of ECM components, mostly induced by MMPs. In addition, MMPs cleave large endothelin molecule producing smaller vasoactive fragments with a consequent activation of VSMCs and vasoconstriction [30]. Blood samples, of hypertensive subjects with atherosclerosis, show elevated levels of MMP-9 mRNA, whereas similar levels of TIMP-1 mRNA were found in 


\section{Kidney \\ Blood Pressure Research}

comparison with normotensive or hypertensive subjects without atherosclerosis [33]. Tan et al demonstrated an increased concentration of MMP-9 and also of TIMP-1 in hypertensive subjects, positively correlated with carotid-femoral pulse wave velocity (PWV), but not with carotid-radial PWV [34]. This evidence suggested an implication of MMP-9 and its inhibitor in large arteries stiffness, but not in small muscular arterial elasticity [34]. However, MMP-9 polymorphisms are associated with higher MMP-9 levels, isolated systolic arterial hypertension [35] and carotid-femoral pulse wave velocity [36].

MMPs and hypertension-induced cardiac remodelling

Franz et al have examined hypertensive subjects with left ventricular hypertrophy observing higher levels of TIMP1, TIMP-2 and TIMP-4 compared to controls, but also elevated MMP-9 levels, especially in concentric hypertrophy [37]. Saglam et al have demonstrated higher levels of MMP3 and MMP-9 concentrations in hypertensive subjects with ventricular hypertrophy and a statistical correlation of these MMPs with left ventricular posterior wall thickness and Doppler indices of diastolic dysfunction [38]. Similarly, Ahmed et al have found an increased MMP-9 and TIMP-1 concentration in subjects with left ventricular hypertrophy and higher levels of TIMP-1 in those with chronic heart failure (CHF) [39]. TIMP-1 seems to be correlated to left ventricular mass and to the diastolic dysfunction degree (evaluated as mitral E/A ratio) $[39,40]$. Recently, Ikonomidis et al have observed that the elevated levels of MMP-9 and TIMP-1 in hypertensive subjects are related to an impaired systolic myocardial deformation and to an increased arterial stiffness, evaluated as PWV [41]. Probably, an attenuation of the proteolytic activity of the MMPs, mediated by the elevated levels of tissue inhibitor, produces an accumulation of ECM proteins and, in particular, an increase in collagen content contributing to the development of the hypertensive heart disease (Fig. 3).

Some authors have suggested that an increase in MMP-9, TIMP-1, and in MMP-7 levels could predict the presence of left ventricular hypertrophy, while an increase in

Fig. 2. Possible role of MMPs in vascular remodelling in arterial hypertension.

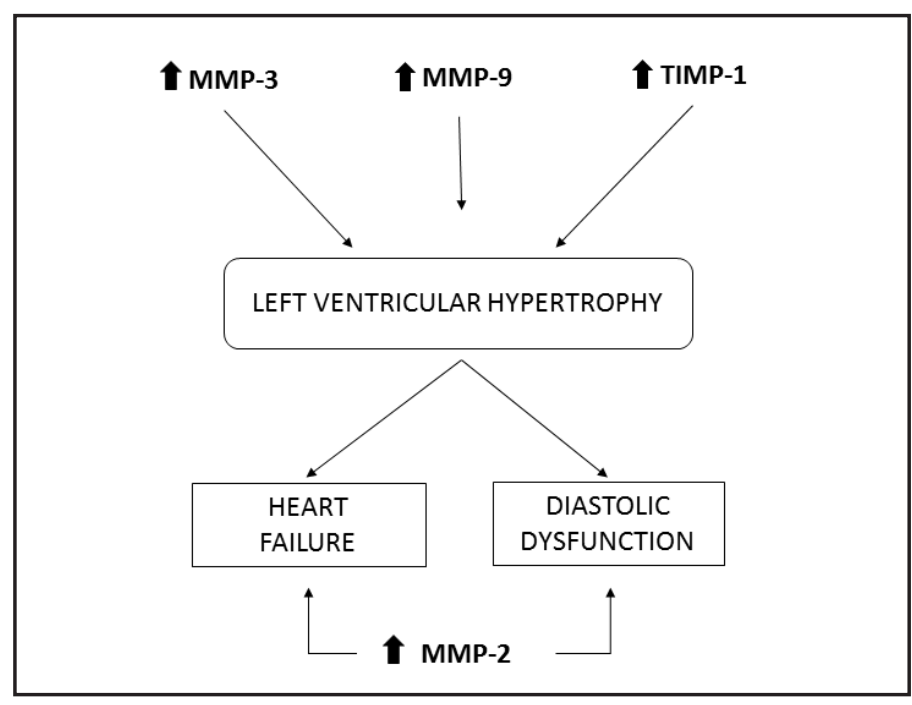

Fig. 3. Possible role of MMPs in cardiac remodelling in arterial hypertension.

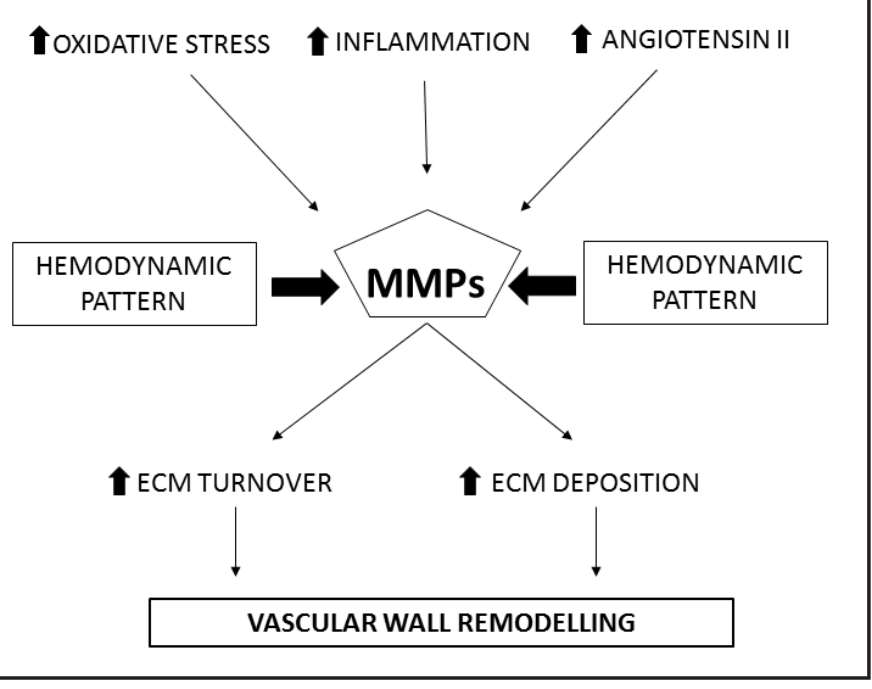




\section{Kidney Blood Pressure Research}

Kidney Blood Press Res 2017;42:347-357

\begin{tabular}{l|l}
\hline DOI: 10.1159/000477785 & (c) 2017 The Author(s). Published by S. Karger AG, Basel \\
Published onlIne: June 12, 2017 & www.karger.com/kbr
\end{tabular}
MMP-2 and a decrease in MMP-8 could predict the presence of diastolic heart failure [42]. Lately, the metanalysis of Marchesi et al has demonstrated elevated concentrations of MMP-9 and TIMP-1 in hypertensive subjects without heart failure and elevated levels of MMP-2 in hypertensives with heart failure, suggesting a role of the MMP-2 in left ventricular remodelling [28]. In animal models, active myocardial MMP-2 expression induces morphological alteration, such as myocyte hyperthrophy, myofilament lysis, sarcomeres destruction and cardiac fibroblast proliferation, resulting in ventricular remodelling [43].

In hypertensive subjects with paroxysmal atrial fibrillation, higher concentrations of TIMP1 are correlated to an increased thickness of interventricular septum, to an increase in left ventricular mass index and to combined concentric and eccentric ventricular hypertrophy, which is prognostically unfavourable [44]. Even the TIMP-2 polymorphisms are significantly associated with the development of atrial fibrillation in subjects with hypertensive heart disease; a decreased expression of TIMP-2 may be responsible for an abnormal deposition of extracellular matrix, atrial fibrosis and structural remodelling promoting arrhythmias [45].

\section{MMPs and antihypertensive molecules}

Many researches have described how some antihypertensive drugs may regulate the MMP activity and concentration. These drugs include angiotensin converting enzyme (ACE) inhibitors, angiotensin receptor blockers (ARBs), calcium channel blockers and some diuretics [46] (Table 1).

\section{ACE inhibitors and angiotensin receptor blockers}

ACE inhibitors and ARBs show antioxidant effects [47-50]. Recently, several studies have examined the influence of these molecules on the MMP/TIMP profile in vivo, keeping in mind the results obtained in experimental models. In fact, in vitro both the ACE inhibitor temocaprilat and the ARB olmesartan inhibited not only the AGE-induced ROS generation but also the MMP-9 expression and activity in cultured smooth muscle cells and in monocytederived macrophages [51]. In samples of carotid artery from spontaneously hypertensive rats (SHR), a chronic treatment with a home-made ACE inhibitor reduced the expression of MMP-2 and MMP-9 and of inflammatory cytokines, such as IL-6 and TNF- $\alpha$ [52]. In the kidney of SHRs, the use of lisinopril or valsartan in monotherapy, or in combination, reduced the mRNA expression of TIMP-1 and MMP-9 [53]. In aortic VSMCs of Wistar rats, angiotensin II induced the expression of MMP-9, while losartan inhibited the expression of MMP-9 while enhancing that of TIMP-1 with a consequent decrease in MMP-9/TIMP-1 ratio in a concentration-dependent manner [54]. In addition, in SHR the renin inhibition with aliskiren reduced the myocardial expression of gelatinases and TIMP-1 after an ischemia/reperfusion injury attenuating the myocardial damage [55].

In a group of 35 hypertensive subjects, Fontana et al have noted no effects after a 8 week enalapril treatment on plasma levels and activity of MMP-2, MMP-9, MMP-8 and their inhibitors [56]. Derosa et al, in a cohort of subjects with arterial hypertension, have obtained a reduction in MMP-2 and MMP-9 concentrations after 13 months of losartan therapy, but the same result was not reached in ramipril-treated patients [57]. Differently, a 3 months period of anti-hypertensive treatment with lisinopril normalizes MMP-9/TIMP-1 ratio produced a reduction of plasma MMP-9 and an increase in TIMP-1 values, as well as in the use of candesartan [58]. 


\section{Kidney Blood Pressure Research}

The effects of ACE inhibitors and ARBs have been examined also in hypertensive subjects with cardiovascular complications. Schieffer et al have observed an improvement of MMP-9/TIMP-1 ratio in subjects with coronary artery disease treated with irbesartan or enalapril [59].

Hypertensive subjects with a high-degree of internal carotid artery stenosis, treated with irbesartan for 4 months, presented a reduced expression of MMP-2 and MMP-9 in the plaque areas of intense macrophage infiltration and a decreased inflammatory reaction [60]. The authors have suggested that the effect of irbesartan on plaque stabilization could be mediated by the inhibition of macrophages activity and the reduction of the oxidative stress. Other authors have demonstrated that a treatment with irbesartan reduced also the levels of collagenases MMP-1 and MMP-8 in subjects with high-degree carotid stenosis, but increased elastin degradation, indicating that the MMPs are not involved in elastin degradation of the atheroma [61].

The effects of ACE inhibitors and ARBs on MMPs levels seem to be mediated by different mechanisms: the inhibition of angiotensin II activity on MMPs expression, the antioxidant and anti-inflammatory effects. In addition, Yamamoto et al demonstrated that ACE inhibitors bind the active site of MMP-9 decreasing its activity [62,63].

\section{Calcium channel blockers (CCBs)}

Animal models (rats) with renovascular hypertension treated with nifedipine, nimodipine, or amlodipine present a reduction of the oxidative stress and MMP-2 expression in thoracic aorta, inhibiting the vascular remodelling [64]. Similarly, a therapy with amlodipine and atorvastatin suppressed MMP-2 activity in the aorta of mice infused with angiotensin II for a period of 28 days [65]. It has been suggested that amlodipine decreases MMP- 2 expression through the protein tyrosin kinase pathway [66]. Nifedipine and lercanidipine suppress the expression of inducible nitric oxide synthase mRNA, attenuate the TNF- $\alpha$ production and decrease the MMP-2, and MMP-9 expression and activity in VSMCs of rats treated with inflammatory stimuli [67]. In hypertensive rats, a treatment with nifedipine for 9 or 12 weeks reduced MMP-2 activity, left ventricular remodelling and cardiac dysfunction, independently of its antihypertensive action [68]. Lercanidipine promoted similar effects in diabetic rats [69]. In human macrophages treated with lacidipine for 24 hours, an evident decrease in MMP-9 and TIMP-1 expression has been observed [70].

In a group of hypertensive subjects, Martinez et al have demonstrated that the treatment with lercanidipine reduced MMP-9 plasma concentrations without affecting TIMP-1 or MMP2 levels [71]. In 48 hypertensive subjects treated with olmesartan, the combination therapy with azelnidipine induced a reduction in MMP-2 levels and improved the arterial stiffness, differently from indapamide [72]. Azelnidipine seems to reduce the MMP-2 and MMP-9 gene expression as a pleiotropic antinflammatory effect, as it inhibits the macrophage infiltration into the vascular wall and the expression of proinflammatory cytokines [73]. Derosa et al have examined a group of 151 hypertensive subjects treated with losartan in combination with barnidipine or lercanidipine; both the CCBs have a slight reduction of MMP-2 and MMP9 plasma levels, even if the decrease was not statistically evident [74]. However, Nakamura et al have demonstrated that telmisartan, but not amlodipine reduced MMP-9 levels in hypertensive subjects with chronic renal failure, suggesting that ARBs are more effective in this kind of patients [75].

\section{Diuretics}

Ceron etal [76] have studied the effects on animal models with renovascular hypertension, after a combined treatment with hydrochlorothiazide and spironolactone on MMP activity and vascular remodelling. They observed that the treatment with the two molecules, or the combination of the two, induced antioxidant effects and attenuated MMP-2 up-regulation. They suggested that the antioxidant action of the diuretics was due to the direct inhibition of vascular NADPH oxidase activity [76]. In animal models with hypertensive heart failure, 


\section{Kidney Blood Pressure Research}

eplerenone improved the cardiac remodelling decreasing the activity of MMP-2, MMP-7, MMP-12 and MMP-13 and regulating the expression of ECM proteins [77]. The data obtained from experimental studies demonstrate that aldosterone increases the expression of MMP9 mRNA and the release of total and active MMP-9 proteins by human polymorphonuclear cells [78]. The actions of the aldosterone antagonists in humans have been evaluated mainly in subjects with chronic heart failure (CHF) than in hypertensive subjects. Li et al have demonstrated that spironolactone enhanced the cardiac function and significantly decreased plasma levels of MMP-1 and MMP-9 and the MMP-9/TIMP-1 ratio [79]. Similarly, Ogino et al have treated CHF subjects with spironolactone or furosemide for 16 weeks and observed a significant decrease in MMP-2 and MMP-9 levels only in the spironolactone-treated subgroup [80]. Derosa et al have evaluated the effects of canrenone on blood pressure and plasma biomarkers of vascular remodelling in subjects with metabolic syndrome; compared to a placebo treatment, canrenone significantly decreased blood pressure values, MMP-2 and MMP-9 concentrations [81].

\section{Conclusion}

Arterial hypertension is a recognized cause of atherosclerosis and cardiovascular events. The alterations in the composition and structure of the ECM are primary determinants in hypertension-induced vascular remodelling, these are largely mediated by an impairment in MMPs/TIMPs balance. On the contrary, the MMP inhibition mitigates the arterial remodelling of animal models with hypertension and atherosclerosis, as well as the arteral remodelling of humans. Therefore, a reasonable therapeutic strategy may be advantageous in hypertensive subjects in order to decrease the risk of cardiovascular complications.

\section{Disclosure Statement}

The authors declare that they have no conflict of interests.

\section{References}

$>1$ Chen Q Jin M, Yang F, Zhu J, Xiao Q Zhang L: Matrix metalloproteinases: inflammatory regulators of cell behaviors in vascular formation and remodeling. Mediators Inflamm 2013;2013:928315.

-2 Belo VA, Guimarães DA, Castro MM: Matrix Metalloproteinase 2 as a Potential Mediator of Vascular Smooth Muscle Cell Migration and Chronic Vascular Remodeling in Hypertension. J Vasc Res 2015;52:221-231.

3 Basu R, Lee J, Morton JS, Takawale A, Fan D, Kandalam V, Wang X, Davidge ST, Kassiri Z: TIMP3 is the primary TIMP to regulate agonist-induced vascular remodelling and hypertension. Cardiovasc Res 2013;98:360-371.

4 Raffetto JD, Khalil RA: Matrix Metalloproteinases and their Inhibitors in Vascular Remodeling and Vascular Disease. Biochem Pharmacol 2008;75:346-359.

5 Bourbolia D, Stetler-Stevenson WG: Matrix metalloproteinases (MMPs) and tissue inhibitors of metalloproteinases (TIMPs): Positive and negative regulators in tumor cell adhesion. Sem Cancer Biol 2010;20:161-168.

6 Jaiswal A, Chhabra A, Malhotra U, Kohli S, Rani V: Comparative analysis of human matrix metalloproteinases: Emerging therapeutic targets in diseases. Bioinformation 2011;6:23-30.

-7 Kwiatkowska E, Domanski L, Bober J, Safranow K, Romanowski M, Pawlik A, Kwiatkowski S, Ciechanowski K: Urinary Metalloproteinases-9 and -2 and Their Inhibitors TIMP-1 and TIMP-2 are Markers of Early and Long-Term Graft Function After Renal Transplantation. Kidney Blood Press Res 2016;41:288-297. 


\section{Kidney \\ Blood Pressure Research}

8 Amalinei C, Caruntu ID, Balan RA: Biology of metalloproteinases. Rom J Morphol Embryol 2007;48:323334.

9 Kar S, Subbaram S, Carrico PM, Melendez JA: A critical link between free radicals, matrix remodeling and degenerative disease. Respir Physiol Neurobiol 2010;174:299-306.

10 Al-Hamodi Z, Ismail IS, Saif-Ali R, Ahmed KA, Muniandy S: Association of plasminogen activator inhibitor-1 and tissue plasminogen activator with type 2 diabetes and metabolic syndrome in Malaysian subjects. Cardiovasc Diabetol 2011;10:23.

11 Hansson J, Vasan RS, Anlov J, Ingelsson E, Lind L, Larsson A, Michaelsson K, Sundstrom J: Biomarkers of Extracellular Matrix Metabolism (MMP-9 and TIMP-1) and Risk of Stroke, Myocardial Infarction, and Cause-Specific Mortality: Cohort Study. PLoS ONE 2011;6:e16185.

12 Viappiani S, Nicolescu AC, Holt A, Sawicki G, Crawford BD, León H, van Mulligen T, Schulz R: Activation and modulation of $72 \mathrm{kDa}$ matrix metalloproteinase- 2 by peroxynitrite and glutathione. Biochem Pharmacol 2009;77:826-834.

13 Cheng C, Tempel D, van Haperen R, van Damme L, Algür M, Krams R, de Crom R: Activation of MMP8 and MMP13 by angiotensin II correlates to severe intra-plaque hemorrhages and collagen breakdown in atherosclerotic lesions with a vulnerable phenotype. Atherosclerosis 2009;204:26-33.

14 Odenbach J, Wang X, Cooper S, Chow FL, Oka T, Lopaschuk G, Kassiri Z, Fernandez-Patron C: MMP-2 mediates angiotensin II-induced hypertension under the transcriptional control of MMP-7 and TACE. Hypertension 2011;57:123-130.

15 Newby AC: Metalloproteinases expression in monocytes and macrophages and its relationship to atherosclerotic plaque instability. Arterioscler Thromb Vasc Biol 2008;28:2108-2014.

16 Brew K, Nagase H: The tissue inhibitors of metalloproteinases (TIMPs): An ancient family with structural and functional diversity. Biochim Biophys Acta 2010;1803:55-71.

17 Hopps E, Caimi G: Matrix metalloproteinases in metabolic syndrome. Eur J Intern Med 2012;23:99-104.

18 Hopps E, Lo Presti R, Montana M, Noto D, Averna MR, Caimi G: Gelatinases and their tissue inhibitors in a group of subjects with metabolic syndrome. J Investig Med 2013;61:978-83.

19 Hopps E, Lo Presti R, Montana M, Canino B, Averna MR, Caimi G: Study of the correlations among some parameters of the oxidative status, gelatinases, and their inhibitors in a group of subjects with metabolic syndrome. Mediators Inflamm 2014;2014:510619.

20 Hopps E, Canino B, Montana M, Calandrino V, Urso C, Lo Presti R, Caimi G: Gelatinases and their tissue inhibitors in a group of subjects with obstructive sleep apnea syndrome. Clin Hemorheol Microcirc 2015;62:27-34.

21 Hopps E, Lo Presti R, Montana M, Canino B, Calandrino V, Caimi G: Analysis of the correlations between oxidative stress, gelatinases and their tissue inhibitors in the human subjects with obstructive sleep apnea syndrome. J Physiol Pharmacol 2015;66:803-810.

22 Gkaliagkousi E, Doumas M, Gavriilaki E, Triantafyllou A, Vogiatzis K, Anyfanti P, Petidis K, Douma S: Elevated levels of MMP-9 in untreated patients with stage I essential hypertension. Clin Exp Hypertens 2012;34:561-566.

-23 Tayebjee MH, Nadar S, Blann AD, Gareth Beevers D, MacFadyen RJ, Lip GY: Matrix metalloproteinase-9 and tissue inhibitor of metalloproteinase-1 in hypertension and their relationship to cardiovascular risk and treatment: a substudy of the Anglo-Scandinavian Cardiac Outcomes Trial (ASCOT). Am J Hypertens 2004;17:764-769.

-24 Fontana V, Silva PS, Belo VA, Antonio RC, Ceron CS, Biagi C, Gerlach RF, Tanus-Santos JE: Consistent Alterations of Circulating Matrix Metalloproteinases Levels in Untreated Hypertensives and in Spontaneously Hypertensive Rats: A Relevant Pharmacological Target. Basic Clin Pharmacol Toxicol 2011;109:130-137.

25 Derosa G, D'Angelo A, Ciccarelli L, Piccinni MN, Pricolo F, Salvadeo S, Montagna L, Gravina A, Ferrari I, Galli S, Paniga S, Tinelli C, Cicero AF: Matrix metalloproteinase-2, -9, and tissue inhibitor of metalloproteinase-1 in patients with hypertension. Endothelium 2006;13:227-231.

-26 Friese RS, Rao F, Khandrika S, Thomas B, Ziegler MG, Schmid-Schonbein GW, O'Connor DT: Matrix Metalloproteinases: Discrete Elevations in Essential Hypertension and Hypertensive End-Stage Renal Disease. Clin Exp Hypertens 2009;31:521-533. 


\section{Kidney \\ Bloód Pressure Research}

27 Dhingra R, Pencina MJ, Schrader P, Wang TJ, Levy D, Pencina K, Siwik DA, Colucci WS, Benjamin EJ, Vasan RS: Relations of Matrix Remodeling Biomarkers to Blood Pressure Progression and Incidence of Hypertension in the Community. Circulation 2009,119:1101-1107.

28 Marchesi C, Dentali F, Nicolini E, Maresca AM, Tayebjee MH, Franz M, Guasti L, Venco A, Schiffrin EL, Lip GY, Grandi AM: Plasma levels of matrix metalloproteinases and their inhibitors in hypertension: a systematic review and meta-analysis. J Hypertens 2012;30:3-16.

29 Hayashi K, Naiki T: Adaptation and remodeling of vascular wall; biomechanical response to hypertension. J Mech Behav Biomed Mater 2009;2:3-19.

-30 Martinez-Lemus LA, Galiñanes EL: Matrix metalloproteinases and small artery remodeling. Drug Discov Today Dis Models 2011;8:21-28.

-31 Feihl F, Liaudet L, Levy BI, Waeber B: Hypertension and microvascular remodelling. Cardiovasc Res 2008;78:274-285.

-32 Harvey A, Montezano AC, Lopes RA, Rios F, Touyz RM: Vascular Fibrosis in Aging and Hypertension: Molecular Mechanisms and Clinical Implications. Can J Cardiol 2016;32:659-668.

-33 Su W, Gao F, Lu J, Wu W, Zhou G, Lu S: Levels of matrix metalloproteinase-9 and tissue inhibitor of metalloproteinase-1 mRNAs in patients with primary hypertension or hypertension-induced atherosclerosis. J Int Med Res 2012;40:986-994.

-34 Tan J, Hua Q Xing X, Wen J, Liu R, Yang Z: Impact of the metalloproteinase-9/tissue inhibitor of metalloproteinase-1 system on large arterial stiffness in patients with essential hypertension. Hypertens Res 2007;30:959-63.

-35 Huang R, Deng L, Shen A, Liu J, Ren H, Xu DL: Associations of MMP1, 3, 9 and TIMP3 genes polymorphism with isolated systolic hypertension in Chinese Han population. Int J Med Sci 2013;10:840-847.

-36 Zhou S, Feely J, Spiers JP, Mahmud A. Matrix metalloproteinase-9 polymorphism contributes to blood pressure and arterial stiffness in essential hypertension. J Hum Hypertens 2007;21:861-867.

-37 Franz M, Berndt A, Altendorf-Hofmann A, Fiedler N, Richter P, Schumm J, Fritzenwanger M, Figulla HR, Brehm BR: Serum levels of large tenascin-C variants, matrix metalloproteinase- 9 , and tissue inhibitors of matrix metalloproteinases in concentric versus eccentric left ventricular hypertrophy. Eur J Heart Fail 2009;11:1057-1062.

-38 Saglam M, Karakaya O, Esen AM, Barutcu I, Dogan S, Karavelioglu Y, Karapinar H, Akgun T, Esen O, Ozdemir N, Turkmen S, Kaymaz C: Contribution of plasma matrix metalloproteinases to development of left ventricular hypertrophy and diastolic dysfunction in hypertensive subjects. Tohoku J Exp Med 2006;208:117-122.

39 Ahmed SH, Clark LL, Pennington WR, Webb CS, Bonnema DD, Leonardi AH, McClure CD, Spinale FG, Zile MR: Matrix metalloproteinases/tissue inhibitors of metalloproteinases: relationship between changes in proteolytic determinants of matrix composition and structural, functional, and clinical manifestations of hypertensive heart disease. Circulation 2006;113:2089-2096.

40 Tayebjee MH, Nadar SK, MacFadyen RJ, Lip GY: Tissue inhibitor of metalloproteinase-1 and matrix metalloproteinase-9 levels in patients with hypertension Relationship to tissue Doppler indices of diastolic relaxation. Am J Hypertens 2004;17:770-774.

-41 Ikonomidis I, Tzortzis S, Triantafyllidi H, Parissis J, Papadopoulos C, Venetsanou K, Trivilou P, Paraskevaidis I, Lekakis J: Association of impaired left ventricular twisting-untwisting with vascular dysfunction, neurohumoral activation and impaired exercise capacity in hypertensive heart disease. Eur J Heart Fail 2015;17:1240-1251.

42 Zile MR, Desantis SM, Baicu CF, Stroud RE, Thompson SB, McClure CD, Mehurg SM, Spinale FG: Plasma biomarkers that reflect determinants of matrix composition identify the presence of left ventricular hypertrophy and diastolic heart failure. Circ Heart Fail 2011;4:246-256.

43 Azevedo A, Prado AF, Antonio RC, Issa JP, Gerlach RF: Matrix metalloproteinases are involved in cardiovascular diseases. Basic Clin Pharmacol Toxicol 2014;115:301-314.

44 Khezheva FM, Mazur NA, Masenko VP: Metalloproteinase activity of the blood in patients with arterial hypertension with paroxysmal form of atrial fibrillation. Kardiologiia 2007;47:10-14.

45 Gai X, Zhang Z, Liang Y, Chen Z, Yang X, Hou J, Lan X, Zheng W, Hou J, Huang M: MMP-2 and TIMP-2 gene polymorphisms and susceptibility to atrial fibrillation in Chinese Han patients with hypertensive heart disease. Clin Chim Acta 2010;411;719-724. 


\section{Kidney \\ Blood Pressure Research}

Hopps et al.: MMPs in Hypertension

46 Hopps E, Caimi G: Matrix metalloproteases as a pharmacological target in cardiovascular diseases. Eur Rev Med Pharmacol Sci 2015;19:2583-2589.

47 Namikoshi T, Tomita N, Satoh M, Haruna Y, Kobayashi S, Komai N, Sasaki T, Kashihara N: Olmesartan ameliorates renovascular injury and oxidative stress in Zucker obese rats enhanced by dietary protein. Am J Hypertens 2007;20:1085-1091.

48 Pei Y, Xu Y, Ruan J, Rong L, Jiang M, Mo Y, Jiang X: Plasma oxidative stress level of IgA nephropathy in children and the effect of early intervention with angiotensin-converting enzyme inhibitors. J Renin Angiotensin Aldosterone Syst 2016;17:1470320316647240.

-49 Onuigbo MA: RAAS inhibition and cardiorenal syndrome. Curr Hypertens Rev 2014;10:107-111.

-50 Tousoulis D, Psaltopoulou T, Androulakis E, Papageorgiou N, Papaioannou S, Oikonomou E, Synetos A, Stefanadis C: Oxidative stress and early atherosclerosis: novel antioxidant treatment. Cardiovasc Drugs Ther 2015;29:75-88.

-51 Kamioka M, Ishibashi T, Sugimoto K, Uekita H, Nagai R, Sakamoto N, Ando K, Ohkawara H, Teramoto T, Maruyama Y, Takeishi Y: Blockade of renin-angiotensin system attenuates advanced glycation end products-mediated signaling pathways. J Atheroscler Thromb 2010;17:590-600.

52 Fang H, Chen W, Gao Y, Shen Y, Luo M: Molecular mechanisms associated with Angiotensin-converting enzyme-inhibitory peptide activity on vascular extracellular matrix remodeling. Cardiology 2014;127:247255.

53 Cheng X, Zhou Q, Lin S, Wu R: Fosinopril and valsartan intervention in gene expression of Klotho, MMP-9, TIMP-1, and PAI-1 in the kidney of spontaneously hypertensive rats. Zhong Nan Da Xue Xue Bao Yi Xue Ban 2010;35:1048-1056.

54 Guo YS, Wu ZG, Yang JK, Chen XJ: Impact of losartan and angiotensin II on the expression of matrix metalloproteinase- 9 and tissue inhibitor of metalloproteinase- 1 in rat vascular smooth muscle cells. Mol Med Rep 2015;11:1587-1594.

-55 Zhang W, Han Y, Meng G, Bai W, Xie L, Lu H, Shao Y, Wei L, Pan S, Zhou S, Chen Q, Ferro A, Ji Y: Direct renin inhibition with aliskiren protects against myocardial ischemia/reperfusion injury by activating nitric oxide synthase signaling in spontaneously hypertensive rats. J Am Heart Assoc 2014;3:e000606.

56 Fontana V, Silva PS, Izidoro-Toledo TC, Biagi C, Oliveira EB, Gerlach RF, Tanus-Santos JE: Comprehensive evaluation of the effects of enalapril on matrix metalloproteinases levels in hypertension. Cardiovasc Drugs Ther 2012;26:511-519.

57 Derosa G, Maffioli P, Ferrari I, Palumbo I, Randazzo S, Fogari E, D'Angelo A, Cicero AF: Different actions of losartan and ramipril on adipose tissue activity and vascular remodeling biomarkers in hypertensive patients. Hypertens Res 2011;34:145-151.

58 Onal IK, Altun B, Onal ED, Kirkpantur A, Oz SG, Turgan C: Serum levels of MMP-9 and TIMP-1 in primary hypertension and effect of antihypertensive treatment. Eur J Int Med 2009;20:369-372.

-59 Schieffer B, Bunte C, Witte J, Hoeper K, Boger RH, Schwedhelm E, Drexler H: Comparative Effects of AT1Antagonism and Angiotensin-Converting Enzyme Inhibition on Markers of Inflammation and Platelet Aggregation in Patients With Coronary Artery Disease. J Am Coll Cardiol 2004,44:362-368.

60 Cipollone F, Fazia M, Iezzi A, Pini B, Cuccurullo C, Zucchelli M, de Cesare D, Ucchino S, Spigonardo F, De Luca M, Muraro R, Bei R, Bucci M, Cuccurullo F, Mezzetti A: Blockade of the angiotensin II type 1 receptor stabilizes atherosclerotic plaques in humans by inhibiting prostaglandin E2-dependent matrix metalloproteinase activity. Circulation 2004;109:1482-1488.

61 Clancy P, Seto SW, Koblar SA, Golledge J: Role of the angiotensin converting enzyme 1/angiotensin II/angiotensin receptor 1 axis in interstitial collagenase expression in human carotid atheroma. Atherosclerosis 2013;229:331-337.

62 Yamamoto D, Takai S, Miyazaki M: Inhibitory profiles of captopril on matrix metalloproteinase-9 activity. Eur J Pharmacol 2008;588:277-279.

63 Jin Y, Han HC, Lindsey ML: ACE inhibitors to block MMP-9 activity: new functions for old inhibitors. J Mol Cell Cardiol 2007;43:664-666.

64 Marçal DM, Rizzi E, Martins-Oliveira A, Ceron CS, Guimaraes DA, Gerlach RF, Tanus-Santos JE: Comparative study on antioxidant effects and vascular matrix metalloproteinase-2 downregulation by dihydropyridines in renovascular hypertension. Naunyn Schmiedebergs Arch Pharmacol 2011;383:35-44. 


\section{Kidney \\ Blood Pressure Research}

65 Takahashi K, Matsumoto Y, Do e Z, Kanazawa M, Satoh K, Shimizu T, Sato A, Fukumoto Y, Shimokawa H: Combination therapy with atorvastatin and amlodipine suppresses angiotensin II-induced aortic aneurysm formation. PLoS One 2013;8:e72558.

66 Yue H, Uzui H, Shimizu H, Nakano A, Mitsuke Y, Ueda T, Lee JD: Different effects of calcium channel blockers on matrix metalloproteinase-2 expression in cultured rat cardiac fibroblasts. J Cardiovasc Pharmacol 2004;44:223-230.

67 Yeh JL, Hsu JH, Liang JC, Chen IJ, Liou SF: Lercanidipine and labedipinedilol--A attenuate lipopolysaccharide/interferon- $\gamma$-induced inflammation in rat vascular smooth muscle cells through inhibition of HMGB1 release and MMP-2, 9 activities. Atherosclerosis 2013;226:364-372.

68 Yamada T, Nagata K, Cheng XW, Obata K, Saka M, Miyachi M, Naruse K, Nishizawa T, Noda A, Izawa H, Kuzuya M, Okumura K, Murohara T, Yokota M: Long-term administration of nifedipine attenuates cardiac remodeling and diastolic heart failure in hypertensive rats. Eur J Pharmacol 2009;615:163-170.

69 Martinez ML, Rizzi E, Castro MM, Fernandes K, Bendhack LM, Gerlach RF, Tanus-Santos JE: Lercanidipine decreases vascular matrix metalloproteinase- 2 activity and protects against vascular dysfunction in diabetic rats. Eur J Pharmacol 2008;599:110-116.

70 Bellosta S, Canavesi M, Favari E, Cominacini L, Gaviraghi G, Fumagalli R, Paoletti R, Bernini F: Lacidipine [correction of Lalsoacidipine] modulates the secretion of matrix metalloproteinase- 9 by human macrophages. J Pharmacol Exp Ther 2001;296:736-743.

71 Martinez ML, Lopes LF, Coelho EB, Nobre F, Rocha JB, Gerlach RF, Tanus-Santos JE: Lercanidipine reduces matrix metalloproteinase-9 activity in patients with hypertension. J Cardiovasc Pharmacol 2006;47:117122.

72 Uzui H, Morishita T, Nakano A, Amaya N, Fukuoka Y, Ishida K, Arakawa K, Lee JD, Tada H: Effects of combination therapy with olmesartan and azelnidipine on serum osteoprotegerin in patients with hypertension. J Cardiovasc Pharmacol Ther 2014;19:304-309.

-73 Kurobe H, Matsuoka Y, Hirata Y, Sugasawa N, Maxfield MW, Sata M, Kitagawa T: Azelnidipine suppresses the progression of aortic aneurysm in wild mice model through anti-inflammatory effects. J Thorac Cardiovasc Surg 2013;146:1501-1508.

74 Derosa G, Mugellini A, Pesce RM, D'Angelo A, Maffioli P: Barnidipine compared to lercanidipine in addition to losartan on endothelial damage and oxidative stress parameters in patients with hypertension and type 2 diabetes mellitus. BMC Cardiovasc Disord 2016;16:66.

75 Nakamura T, Inoue T, Suzuki T, Kawagoe Y, Ueda Y, Koide H, Node K: Comparison of renal and vascular protective effects between telmisartan and amlodipine in hypertensive patients with chronic kidney disease with mild renal insufficiency. Hypertens Res 2008;31:841-850.

76 Ceron CS, Castro MM, Rizzi E, Montenegro MF, Fontana V, Salgado MC, Gerlach RF, Tanus-Santos JE: Spironolactone and hydrochlorothiazide exert antioxidant effects and reduce vascular matrix metalloproteinase- 2 activity and expression in a model of renovascular hypertension. Br J Pharmacol 2010;160:77-87.

77 Muñoz-Pacheco P, Ortega-Hernández A, Caro-Vadillo A, Casanueva-Eliceiry S, Aragoncillo P, Egido J, Fernández-Cruz A, Gómez-Garre D: Eplerenone enhances cardioprotective effects of standard heart failure therapy through matricellular proteins in hypertensive heart failure. J Hypertens 2013;31:2309-2318.

-78 Gilet A, Zou F, Boumenir M, Frippiat JP, Thornton SN, Lacolley P, Ropars A: Aldosterone up-regulates MMP-9 and MMP-9/NGAL expression in human neutrophils through p38, ERK1/2 and PI3K pathways. Exp Cell Res 2015;331:152-163.

-79 Li MJ, Huang CX, Okello E, Yanhong T, Mohamed S: Treatment with spironolactone for 24 weeks decreases the level of matrix metalloproteinases and improves cardiac function in patients with chronic heart failure of ischemic etiology. Can J Cardiol 2009;25:523-526.

80 Ogino K, Kinugasa Y, Kato M, Yamamoto K, Hisatome I, Anker SD, Doehner W: Spironolactone, not furosemide, improved insulin resistance in patients with chronic heart failure. Int J Cardiol 2014;171:398403.

81 Derosa G, Romano D, Bianchi L, D'Angelo A, Maffioli P: The effects of canrenone on inflammatory markers in patients with metabolic syndrome. Ann Med 2015;47:47-52. 